\title{
Spontaneous intracranial hypotension secondary to congenital spinal dural ectasia and genetic mosaicism for tetrasomy 10p: illustrative case
}

\author{
Peyton L. Nisson, MD, ${ }^{1}$ Rhona Schreck, PhD, ${ }^{2}$ John M. Graham, Jr., MD, ScD, ${ }^{3}$ Marcel M. Maya, MD, ${ }^{4}$ and Wouter I. Schievink, MD ${ }^{1}$ \\ ${ }^{1}$ Department of Neurosurgery, ${ }^{2}$ Department of Pathology, ${ }^{3}$ Medical Genetics, Department of Pediatrics, and ${ }^{4}$ Department of Radiology, Cedars-Sinai Medical Center, Los \\ Angeles, California
}

\begin{abstract}
BACKGROUND Spontaneous intracranial hypotension has historically been a poorly understood pathology that is often unrecognized and undertreated. Even more rarely has it been described in pediatric patients with an otherwise benign past medical history.

OBSERVATIONS Herein the authors describe one of the youngest patients ever reported, a 2-year-old girl who developed severe headaches, nausea, and vomiting and experienced headache relief after lying down. Imaging revealed tonsillar herniation $14 \mathrm{~mm}$ below the foramen magnum, presumed to be a Chiari malformation, along with extensive dural cysts starting from thoracic level T2 down to the sacrum. She was found to have streaky skin pigmentary variation starting from the trunk down to her feet. Genetic analysis of skin biopsies revealed mosaicism for an isodicentric marker chromosome (10p15.3-10q11.2 tetrasomy) in 27\%-50\% of cells. After undergoing a suboccipital and cervical decompression at an outside institution, she continued to be symptomatic. She was referred to the authors' hospital, where she was diagnosed with spontaneous intracranial hypotension.

LESSONS After receiving a series of epidural blood patches, the patient experienced almost complete relief of her symptoms. To the authors' knowledge, this is the first time this chromosomal anomaly has ever been reported in a living child, and this may represent a new genetic association with dural ectasia.
\end{abstract}

https://thejns.org/doi/abs/10.3171/CASE213

KEYWORDS intracranial hypotension; genetic mosaicism; tetrasomy 10p; dural ectasia; epidural blood patch

Once considered extremely rare, spontaneous intracranial hypotension $(\mathrm{SIH})$ represents a poorly recognized disease entity that has recently been diagnosed with increasing frequency. The estimated incidence of 5 in 100,000 is likely an underestimate of the true rate. ${ }^{1}$ The expansion of magnetic resonance imaging (MRI) and awareness within the medical field of this pathology have led to a growing body of literature on this topic. Often patients are misdiagnosed with ailments such as migraine, tension headache, meningitis, transient ischemic attack, and psychogenic disorder before $\mathrm{SIH}$ is diagnosed. ${ }^{2}$ However, in some cases, symptoms can be progressive, eventually becoming debilitating and even life threatening.,

The most common cause of SIH is spinal cerebrospinal fluid (CSF) leak. Patients who are symptomatic classically have positional, orthostatic headaches; however, other symptoms can also develop, including neck pain, nausea, vomiting, vision changes, photophobia, and cognitive abnormalities, to name a few. SIH typically affects patients in the fifth and sixth decades of life, with a mean age of 40 years, and it has also been associated with a spectrum of connective tissue disorders, especially in the pediatric population. ${ }^{1,5,6}$ Only case reports and one case series have been published describing this disease in pediatric patients. $^{6-8}$ Mosaicism for $10 p$ tetrasomy was also identified in the child in the present case, a rare event reported only in a prior fetal report. ${ }^{9}$ We describe the first living patient, to our knowledge, with this genetic variant who had $\mathrm{SIH}$.

\section{Illustrative Case}

The patient was a healthy female born at 38 weeks of gestation via repeat cesarean section, weighing 7 pounds, 1 ounce. She was an otherwise healthy child with normal growth and development. At age 2 years, she began complaining of severe headaches, screaming, "My

ABBREVIATIONS CSF = cerebrospinal fluid; EBP = epidural blood patch; MRI = magnetic resonance imaging; SIH = spontaneous intracranial hypotension. INCLUDE WHEN CITING Published August 16, 2021; DOI: 10.3171/CASE213

SUBMITTED January 2, 2021. ACCEPTED June 14, 2021.

(C) 2021 The authors, CC BY-NC-ND 4.0 (http://creativecommons.org/licenses/by-nc-nd/4.0/). 

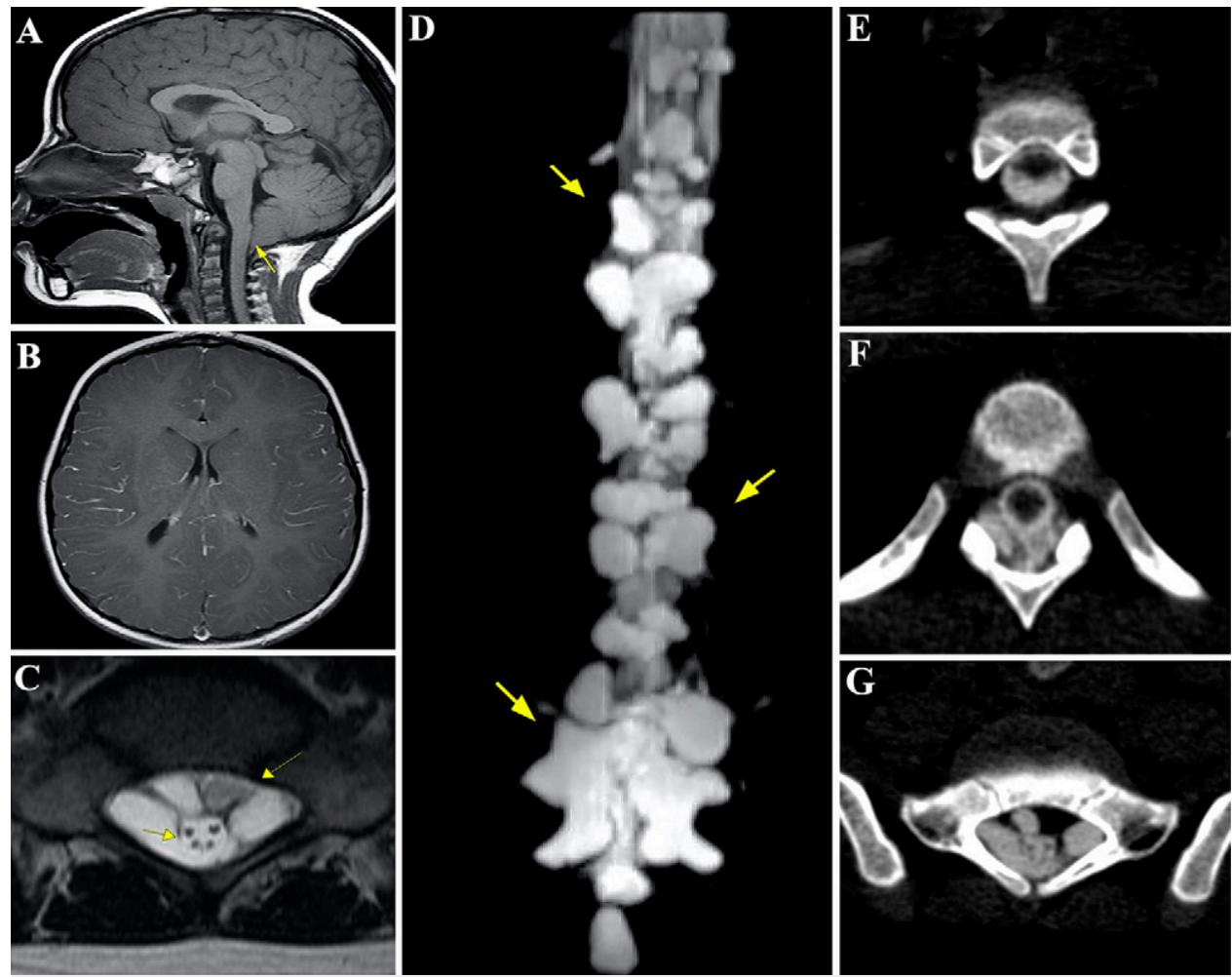

FIG. 1. MRI reveals several findings. A: Sagittal T1 image shows low-lying cerebellar tonsils below the foramen magnum (14 mm), as highlighted by the yellow arrow. There is no flattening present on the pons and on the post-gadolinium sequence (not shown in image), with no hyperemia of the pituitary stalk. B: Axial T1 post-gadolinium sequence shows no pachymeningeal enhancement was present, findings suggestive of SIH but not always present. C: Axial T1 post-intrathecal gadolinium of the lumbar spine reveals multiple dural cysts highlighted by outside yellow arrow, with the normal contour of the thecal sac highlighted with the more central yellow arrow. D: A total spine post-intrathecal gadolinium reconstruction reveals numerous dural cysts and dilations spanning from the thoracic $\mathrm{T} 2$ level to the lumbosacrum as highlighted by the yellow arrows. E-G: Computed tomographic myelogram axial images demonstrate the relatively normal-appearing upper thoracic dura $(\mathbf{E})$, whereas the midthoracic $(\mathbf{F})$ and lower lumbar $(\mathbf{G})$ segments contain large, outpouching diverticula.

head is on fire," along with light and noise sensitivity, nausea, and vomiting. Her parents noticed that she would experience relief from her headaches after lying down. She was eventually taken to a nearby children's hospital, where MRI of the brain revealed low-lying cerebellar tonsils $14 \mathrm{~mm}$ below the foramen magnum (Fig. 1A). There was no pachymeningeal enhancement on post-gadolinium T1-weighted MRI (Fig. 1B). When evaluating her for a cervical syrinx, multiple cysts and dilations of the dura were also found along the spine, extending down to the sacrum, as shown in Fig. $1 \mathrm{C}$ and D. Diagnosed with a Chiari 1 malformation at the outside facility, the patient underwent decompression with dural opening along with a thoracic laminectomy at T5 with biopsy of an epidural mass. The final pathology revealed normal but thinly dilated dura and venous tissue.

After the operation, she experienced improvement of her headaches, but they soon recurred with increasing frequency, accompanied by new onset of double vision. Episodes of bowel and bladder function loss, worsening hypersomnolence, chest tightness, and pressure in her left index finger also developed. Over the next 2 years, she was seen by multiple specialists in several tertiary and quaternary medical centers across the country. It was not until the age of 4 years and 8 months that she was referred to our center for further evaluation of CSF leak.
On examination, the patient was neurologically intact but was found to have hypopigmented streaks starting from her midthoracic region, going down her legs, with the left leg more affected than

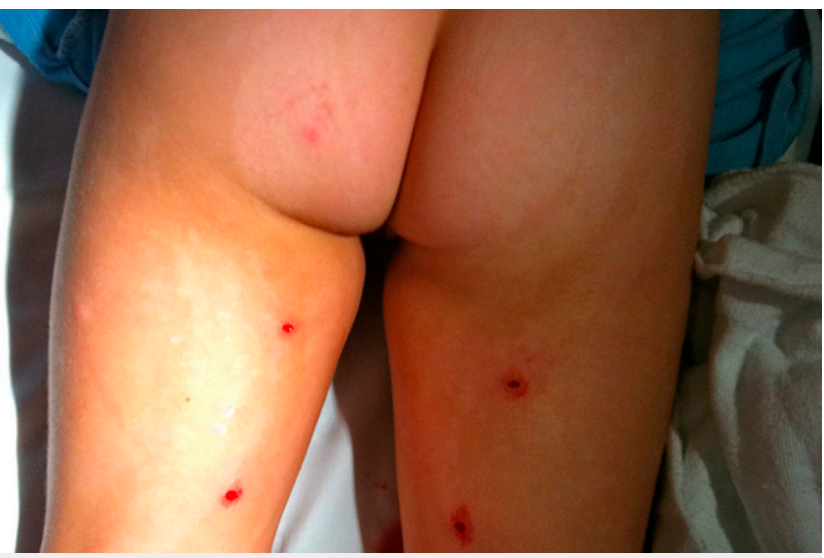

FIG. 2. The patient's lower extremities and buttocks are shown with several erythematous and hypopigmented macules present, consistent with hypomelanosis of Ito. 


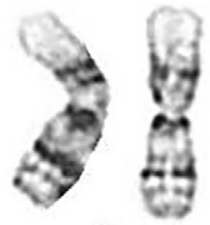

1

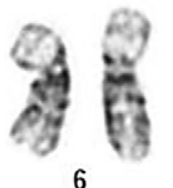

6

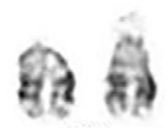

13

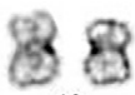

19
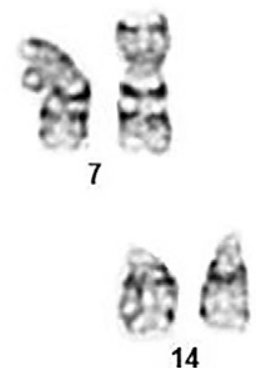

14

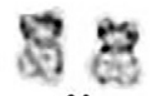

20

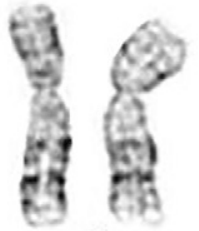

2

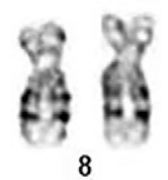

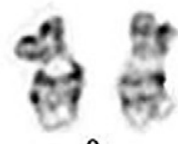

9

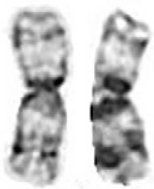

3

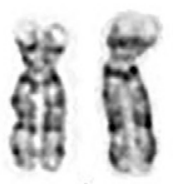

4

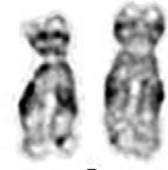

5

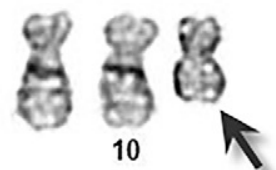

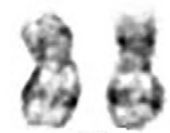

11

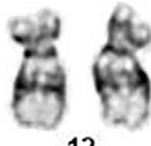

12

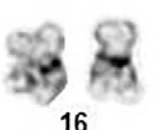

16

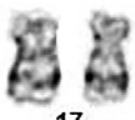

17

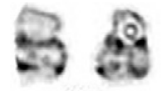

18

FIG. 3. Abnormal karyotype with arrow pointing to marker chromosome identified as isodicentric 10p.

the right. Consistent with hypomelanosis of Ito, this prompted a referral for a genetic work-up (Fig. 2). Per the patient's family, these streaks had been present since birth, becoming more prominent after she spent time in the sun.

The results of outside evaluations at age 2 years by karyotype analysis and chromosomal microarray were reported to be normal in peripheral blood. Sequencing of some of the most common genes causing dural ectasia, including FNB1, TGFBR1, TGFBR2, and COL5A2, did not reveal any pathogenic variants. The following laboratory values were all within normal limits with some slight elevations but none consistent with a genetic disease: lactate, ammonia, urine organic acids, and serum amino acids. Repeat studies at age 4 confirmed a normal blood karyotype, 46,XX. However, karyotype analysis of skin biopsies from differently pigmented areas showed two populations of cells, with one having only normal $46, X X$ cells and the other (50\%) having 47 chromosomes due to the presence of a supernumerary, medium-sized, metacentric marker chromosome (47,XX,+mar), as shown in Fig. 3. Chromosomal microarray analysis of the skin identified this marker chromosome as an isodicentric chromosome 10 [arr 10p15.3q11.22(135,655-47,688,677)x2 4] present in $27 \%-50 \%$ of cells from various samples from the hypopigmented regions. Thus, the abnormal cells were tetrasomic for all of the short arm of chromosome 10.

The patient underwent a $10-\mathrm{mL}$ epidural blood patch (EBP) at the thoracic T11-12 level under anesthesia with somatosensory evoked potential monitoring. This level was chosen to allow the maximum amount of blood patching at an anatomically accessible and more capacious epidural space.

After this procedure, she experienced complete resolution of her headaches and no longer complained of double vision. For a total of 4 days, she experienced complete relief, but her symptoms recurred. After 1 month, they had all returned, but with lesser intensity, now with transient episodes of lower extremity weakness after a bowel movement, along with a sensation of pins and needles.
Four months after the first EBP, a second one was administered using the same technique. For the next 5 years, the patient experienced a relatively normal life with no missed school days, and she was fully active until she began to have some recurrence of hypersomnolence and worsening headaches. Interval computed topography myelograms and MRI myelograms were all stable between this time period (age 2 to 7 years). A third EBP was administered at this time. At the most recent 2-year follow-up since then, she reported complete resolution of her symptoms with the exception of occasional mild headaches.

\section{Discussion}

\section{Observations}

This case represents one of the youngest patients ever reported with $\mathrm{SIH}$, second to a 1-year-old reported by Adler et al. in 2011. 6,10-18 Despite being evaluated by several specialists spanning multiple tertiary and quaternary medical centers, 2 years elapsed before this patient was correctly diagnosed. Unfortunately, this experience is not unique or an outlier, as historically, the majority of patients with $\mathrm{SIH}$ have a delayed diagnosis. ${ }^{2}$ Despite the vast symptom overlap with other disease states, the presence of positionality in the history should always raise $\mathrm{SIH}$ on the differential diagnosis for clinicians. In this case, we recognized the extensive dural ectasia in the setting of orthostatic headaches as clear evidence of the patient's intracranial hypotension. Although spine surgery and traumatic injury are well recognized risk factors for spinal CSF leak, spontaneous leak may also be possible. ${ }^{19-21}$ Comparatively, pediatric patients have a higher rate of connective tissue disorder than adults with $\mathrm{SIH}^{6}$ Of the several genetic disorders cited in association with dural ectasia (Table 1), only Ehlers-Danlos type 2, Stickler-like syndrome, Marfan syndrome and Marfan-like syndrome, neurofibromatosis type 1 , congenital contractual arachnodactyly-like 
TABLE 1. Known syndromes and genetic mutations associated with dural ectasia

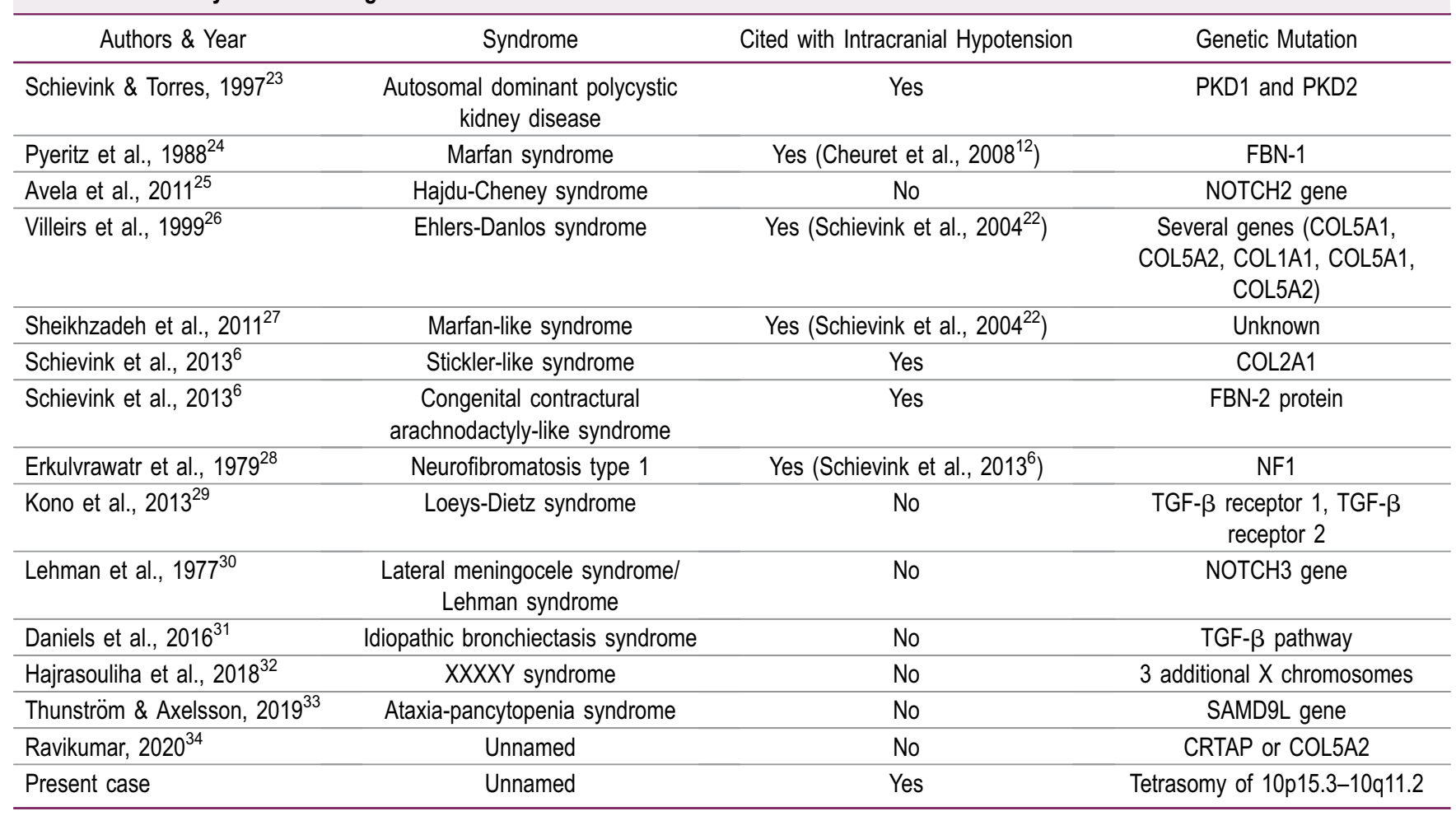

Syndromes that have been cited with intracranial hypotension at a date later than when dural ectasia was reported are provided in column 3 from the left.

syndrome, and autosomal dominant polycystic kidney disease have been cited in association with $\mathrm{SIH}^{14,22}$

\section{Lessons}

Until now, no surviving human with tetrasomy of 10p15.3-10q11.2 has been reported. The only other example involves a fetus with multiple anomalies on ultrasound. ${ }^{9}$ The unlikely concurrence of a chromosomal anomaly and dural ectasia occurring in the same patient, especially with the diverticula arising at the same anatomical level as the level where the streaky skin pigmentation started, suggests a causal relationship between this mutation and $\mathrm{SIH}$. Cytogenetic evaluation may be indicated in patients monitored for symptoms associated with $\mathrm{SIH}$. Streaky skin pigmentary dysplasia, sometimes termed "hypomelanosis of Ito," is often a marker for chromosomal mosaicism, which may not be detectable on lymphocyte karyotypes. Thus, a skin fibroblast karyotype may be needed for an accurate diagnosis.

Among the available treatment modalities for $\mathrm{SIH}$, conservative approaches can include bed rest, caffeine, hydration, theophylline, acetazolamide, corticosteroids, and abdominal binder. More invasive measures can consist of epidural injections, intrathecal infusions, and surgical repair. ${ }^{35}$ In this case, the patient's extensive dural cysts, which spanned close to two-thirds of the spine, and her young age prohibited surgery from being considered a viable option. Alternatively, the severity of her symptoms and extensive dural ectasia deterred us from pursuing any of the more conservative therapies. A fibrin glue patch was considered, but because there was no specific location or diverticula being targeted, but rather an expansive area, a blood patch was deemed more appropriate. We thus elected to pursue a trial of EBP, which provided significant improvement.
Mechanistically, limited research exists on this topic. We suspect the patient's thin, dilated dura, as evidenced by pathologic review, was the result of her genetic disorder, making it more permeable to CSF leakage. In addition, the combination of this and the dural cysts may have affected the hydrostatic pressure, leading to the development of SIH. In this paradigm, the EBP provides at least 3 important functions. (1) It serves as a space-occupying fluid within the spinal canal or "pressure patch," augmenting the reduced CSF volume through compression of the dura. ${ }^{36,37}$ (2) Coagulopathic elements within blood act as an obstructive sealant to fluid volume loss, also known as the "plug theory." ${ }^{38}$ (3) The storm of cytokines and inflammation may thicken the dura through sclerosis and/or block the arachnoid granulations, thereby tilting the reabsorptionproduction balance by reducing the rate of reabsorption. ${ }^{39}$

Although $30 \%-90 \%$ of patients with $\mathrm{SIH}$ can experience initial symptom relief after the first EBP, many often require two or more EBPs to achieve persistent relief. ${ }^{40-42}$ In pediatric patients specifically, $40 \%$ have been cited as being sufficiently treated with EBP alone. $^{6}$ The immediate symptom resolution experienced by our patient is consistent with a rise of intracranial pressure after the EBP. Conflicting reports exist for the length of time that this effect persists. A series of post-procedural MRI scans by Beards et al. ${ }^{37}$ revealed that compression resolved after 7 hours. Other reports have cited the presence of extradural space occupying mass up to 4 weeks in an animal model and up to 7 days in a human using myelography. ${ }^{38,43}$ The recurrence of symptoms at the 1-month mark after both EBPs suggested that the "mass effect" of the clot likely dissipated at this point in time. However, the long-standing improvement in her symptoms may have been the result of a net decrease of CSF leakage through the dural thickening/sclerosis and blockage 
of the arachnoid granulation pathway. We suspect the return of her symptoms years after her second EBP could be accounted for by an extension of her axial skeleton, with novel dural growth, once again tipping the axis further toward reabsorption due to her dural ectasia. Future molecular changes that occur within the dura after an EBP in relation to changes over time may help better guide treatment in the future and elucidate potential novel therapeutic agents for the treatment of $\mathrm{SIH}$.

\section{References}

1. Schievink WI. Spontaneous spinal cerebrospinal fluid leaks and intracranial hypotension. JAMA. 2006;295(19):2286-2296.

2. Schievink WI. Misdiagnosis of spontaneous intracranial hypotension. Arch Neurol. 2003;60(12):1713-1718.

3. Schievink WI. Stroke and death due to spontaneous intracranial hypotension. Neurocrit Care. 2013;18(2):248-251.

4. Beck J, Gralla J, Fung C, et al. Spinal cerebrospinal fluid leak as the cause of chronic subdural hematomas in nongeriatric patients. J Neurosurg. 2014;121(6):1380-1387.

5. Reinstein E, Pariani M, Bannykh S, Rimoin DL, Schievink WI. Connective tissue spectrum abnormalities associated with spontaneous cerebrospinal fluid leaks: a prospective study. Eur J Hum Genet. 2013;21(4):386-390.

6. Schievink WI, Maya MM, Louy C, Moser FG, Sloninsky L. Spontaneous intracranial hypotension in childhood and adolescence. J Pediatr. 2013;163(2):504-510.

7. Bladen J, Moosajee M, Renowden S, Carter M, Sainsbury C, Jardine P. Spontaneous intracranial hypotension in adolescence. BMJ Case Rep. 2009;2009:bcr2006096644.

8. Chan EK, Yan B, Ryan MM. Spontaneous intracranial hypotension in childhood: a case report and review of the literature. $J$ Child Neurol. 2011;26(6):761-766.

9. Wu YC, Yu MT, Chen LC, Chen CL, Yang ML. Prenatal diagnosis of mosaic tetrasomy 10p associated with megacisterna magna, echogenic focus of left ventricle, umbilical cord cysts and distal arthrogryposis. Am J Med Genet A. 2003;117A(3):278-281.

10. Bladen J, Moosajee M, Renowden S, Carter M, Sainsbury C, Jardine P. Neurological pictures. Spontaneous intracranial hypotension in adolescence. J Neurol Neurosurg Psychiatry. 2007;78(2):167.

11. Önal $H$, Ersen $A$, Gemici $H$, et al. Acquired Chiari I malformation secondary to spontaneous intracranial hypotension syndrome and persistent hypoglycemia: a case report. J Clin Res Pediatr Endocrinol. 2018;10(4):391-394.

12. Cheuret $\mathrm{E}$, Edouard $\mathrm{T}$, Mejdoubi $\mathrm{M}$, et al. Intracranial hypotension in a girl with Marfan syndrome: case report and review of the literature. Childs Nerv Syst. 2008;24(4):509-513.

13. Rosser T, Finkel J, Vezina G, Majd M. Postural headache in a child with Marfan syndrome: case report and review of the literature. J Child Neurol. 2005;20(2):153-155.

14. Mokri B, Maher CO, Sencakova D. Spontaneous CSF leaks: underlying disorder of connective tissue. Neurology. 2002;58(5):814-816.

15. Milledge JT, Ades LC, Cooper MG, Jaumees A, Onikul E. Severe spontaneous intracranial hypotension and Marfan syndrome in an adolescent. J Paediatr Child Health. 2005;41(1-2):68-71.

16. Yoganathan S, Mariappan R, Sudhakar SV, et al. An unusual cause of chronic headache in an adolescent boy: a case report. Neuropediatrics. 2019;50(6):395-399.

17. Adler F, Gupta N, Hess CP, Dowd CF, Dillon WP. Intraosseous CSF fistula in a patient with Gorham disease resulting in intracranial hypotension. AJNR Am J Neuroradiol. 2011;32(11):E198-E200.

18. Uysal S, Albayram S, Ercan TE. Spontaneous intracranial hypotension: a case report. J Child Neurol. 2008;23(11):1312-1315.
19. Nosik WA. Intracranial hypotension secondary to lumbar nerve sleeve tear. J Am Med Assoc. 1955;157(13):1110-1111.

20. Schievink WI, Ebersold MJ, Atkinson JL. Roller-coaster headache due to spinal cerebrospinal fluid leak. Lancet. 1996; 347(9012): 1409 .

21. Schievink WI, Meyer FB, Atkinson JL, Mokri B. Spontaneous spinal cerebrospinal fluid leaks and intracranial hypotension. J Neurosurg. 1996;84(4):598-605.

22. Schievink WI, Gordon OK, Tourje J. Connective tissue disorders with spontaneous spinal cerebrospinal fluid leaks and intracranial hypotension: a prospective study. Neurosurgery. 2004;54(1):65-71.

23. Schievink WI, Torres VE. Spinal meningeal diverticula in autosomal dominant polycystic kidney disease. Lancet. 1997;349(9060): 1223-1224.

24. Pyeritz RE, Fishman EK, Bernhardt BA, Siegelman SS. Dural ectasia is a common feature of the Marfan syndrome. Am J Hum Genet. 1988;43(5):726-732.

25. Avela K, Valanne L, Helenius I, Mäkitie O. Hajdu-Cheney syndrome with severe dural ectasia. Am J Med Genet A. 2011;155A(3): 595-598.

26. Villeirs GM, Van Tongerloo AJ, Verstraete KL, Kunnen MF, De Paepe AM. Widening of the spinal canal and dural ectasia in Marfan's syndrome: assessment by CT. Neuroradiology. 1999;41(11):850-854.

27. Sheikhzadeh S, Rybczynski M, Habermann CR, et al. Dural ectasia in individuals with Marfan-like features but exclusion of mutations in the genes FBN1, TGFBR1 and TGFBR2. Clin Genet. 2011;79(6):568-574.

28. Erkulvrawatr S, El Gammal T, Hawkins J, Green JB, Srinivasan G. Intrathoracic meningoceles and neurofibromatosis. Arch Neurol. 1979;36(9):557-559.

29. Kono AK, Higashi M, Morisaki H, Morisaki T, Naito H, Sugimura K. Prevalence of dural ectasia in Loeys-Dietz syndrome: comparison with Marfan syndrome and normal controls. PLoS One. 2013;8(9):e75264.

30. Lehman RA, Stears JC, Wesenberg RL, Nusbaum ED. Familial osteosclerosis with abnormalities of the nervous system and meninges. J Pediatr. 1977;90(1):49-54.

31. Daniels ML, Birchard KR, Lowe JR, Patrone MV, Noone PG, Knowles MR. Enlarged dural sac in idiopathic bronchiectasis implicates heritable connective tissue gene variants. Ann Am Thorac Soc. 2016;13(10):1712-1720.

32. Hajrasouliha AR, Moss HE, Maralani PJ, Kaufman L, Grassi MA. Macular detachment associated with anomalous optic nerves and dural ectasia in 49,XXXXY syndrome. Retin Cases Brief Rep. 2018;12(1):39-41.

33. Thunström S, Axelsson M. Leukoencephalopathia, demyelinating peripheral neuropathy and dural ectasia explained by a not formerly described de novo mutation in the SAMD9L gene, ends 27 years of investigations - a case report. BMC Neurol. 2019;19(1):89.

34. Ravikumar S. A case of high intracranial pressure and dural ectasia (5183). Neurology. 2020;94(15 suppl):5183.

35. Mokri B. Spontaneous low pressure, low CSF volume headaches: spontaneous CSF leaks. Headache. 2013;53(7):1034-1053.

36. Kanno H, Yoshizumi T, Nakazato N, Shinonaga M. Predictors of the response to an epidural blood patch in patients with spinal leakage of cerebrospinal fluid. J Clin Neurol. 2020;16(1):1-8.

37. Beards SC, Jackson A, Griffiths AG, Horsman EL. Magnetic resonance imaging of extradural blood patches: appearances from $30 \mathrm{~min}$ to 18 h. Br J Anaesth. 1993;71(2):182-188.

38. DiGiovanni AJ, Galbert MW, Wahle WM. Epidural injection of autologous blood for postlumbar-puncture headache. II. Additional clinical experiences and laboratory investigation. Anesth Analg. 1972;51(2):226-232.

39. Collier CB. Blood patches may cause scarring in the epidural space: two case reports. Int J Obstet Anesth. 2011;20(4):347-351. 
40. Sencakova D, Mokri B, McClelland RL. The efficacy of epidural blood patch in spontaneous CSF leaks. Neurology. 2001;57(10):1921-1923.

41. Cho KI, Moon HS, Jeon HJ, Park K, Kong DS. Spontaneous intracranial hypotension: efficacy of radiologic targeting vs blind blood patch. Neurology. 2011;76(13):1139-1144.

42. Duffy PJ, Crosby ET. The epidural blood patch. Resolving the controversies. Can J Anaesth. 1999;46(9):878-886.

43. Hardy PA. Extradural blood patch after an intradural injection. Anaesthesia. 1988;43(3):251.

\section{Disclosures}

The authors report no conflict of interest concerning the materials or methods used in this study or the findings specified in this paper.

\section{Author Contributions}

Conception and design: Schievink, Nisson, Graham. Acquisition of data: all authors. Analysis and interpretation of data: all authors. Drafting the article: Nisson. Critically revising the article: all authors. Reviewed submitted version of manuscript: all authors. Approved the final version of the manuscript on behalf of all authors: Schievink. Administrative/technical/material support: Nisson, Graham. Study supervision: Schievink.

\section{Correspondence}

Wouter I. Schievink: Cedars-Sinai Medical Center, Los Angeles, CA. wouter.schievink@cshs.org. 